\title{
Photoinduced Change of UV-Absorption and Redox Potential of Alkyne-Bridged Diferrocenyl Azobenzene Derivative
}

\author{
Limin Han, Jianchen Bai, Quanling Suo, Meihua Luo, and Lifeng Zhang \\ Chemical Engineering College, Inner Mongolia University of Technology, Hohhot 010051, China \\ Correspondence should be addressed to Quanling Suo, szj@imut.edu.cn
}

Received 19 June 2008; Accepted 11 August 2008

Recommended by Russell Hughes

An alkynyl-coupled diferrocenylpropane and azobenzene derivative has been synthesized. Photoinduced change of UV-absorbance and shifts of redox potential of synthesized compound were elucidated by time-dependent density function theory (TD-DFT) calculations, indicating that isomerization of trans to cis configuration occurs by UV irradiation.

Copyright ( $) 2008$ Limin Han et al. This is an open access article distributed under the Creative Commons Attribution License, which permits unrestricted use, distribution, and reproduction in any medium, provided the original work is properly cited.

\section{Introduction}

Since the structures and properties of intelligent azo molecules are facilely and reversibly changeable by the application of external physical and chemical stimuli, they have attracted much attention relative to the development of new molecule-based devices [1]. One category of such molecules comprises transition metal complexes with conjugated spacers to azo unit, in which the combination of flexibility of metal $d$ - and azo $\pi$-orbitals can yield unique optical, magnetic, and electronic properties [2-4]. For example, when the ferrocene is covalently bound to an azobenzene, the isomerization of azo functional group may lead to change of intrinsic redox potential of ferrocene [5]. Inversely, isomerization behavior of azo-structure can also be influenced by the connected metal complex [6].

Though attention has been focused on photoisomerization of metal complexes-azobenzene systems, there are no reports on the alkynyl-bridged diferrocene and azo system, especially, for the interpretation of absorbency change of UV-spectrum and electrochemical redox potential shift in this system. In this paper, we synthesized an alkynyl-bridged diferrocenyl azobenzene derivatives by using documental methods [7-10], and investigated the photoinduced azo isomerization and redox potential shift of ferrocene.

\section{Experimental}

2.1. Material Preparation. Diferrocenylpropane and diferrocenypropanyl acetylene (DFA) were prepared by previous methods [11], the Diferrocenylpropanyl acetylene azophenol (DFAA) was synthesized by the Sonogashira coupling reaction of DFA with iodic azophenol (see Scheme 1). Under $\mathrm{N}_{2}$ atmosphere DFA $(165 \mathrm{mg}, 0.51 \mathrm{mmol})$ and iodic azophenol $(162 \mathrm{mg}, 0.5 \mathrm{mmol})$ were stirred in diisopropylamine $(20 \mathrm{~mL})$ with $\mathrm{Pd}\left(\mathrm{PPh}_{3}\right)_{2} \mathrm{Cl}_{2}(6.4 \mathrm{mg}, 0.009 \mathrm{mmol})$ and $\mathrm{CuI}(5.3 \mathrm{mg}, 0.0275 \mathrm{mmol})$ for 20 hours under reflux. The solvent of the resulting orange mixture was removed in vacuum. The residue was dissolved in a minimal amount of $\mathrm{CH}_{2} \mathrm{Cl}_{2}$. The filtrate was concentrated and subjected to chromatographic separation on a neutral alumina column. Elution with hexane-dichloromethane $(4: 1, \mathrm{v} / \mathrm{v})$ afforded a yellow band and red band, the red band product was obtained by recrystallizing from hexane-dichloromethane at $-20^{\circ} \mathrm{C}$. Yield, $55.1 \%$. Anal. Calc: C, 70.28; H, 5.10; N, 4.14. Found: C, 69.79; H, 5.42; N, 4.43\%. IR $(\mathrm{KBr}): 3088[\mathrm{Cp} v \mathrm{C}-\mathrm{H}] ; 2197[\mathrm{C} \equiv \mathrm{C}$, $v \mathrm{C} \equiv \mathrm{C}] ; 1593,1495,\left[\mathrm{C}_{6} \mathrm{H}_{4}, v \mathrm{C}=\mathrm{C}\right] ; 1424[-\mathrm{N}=\mathrm{N}-, v \mathrm{~N}=\mathrm{N}]$; $1265[-\mathrm{OH} \delta \mathrm{O}-\mathrm{H}] ; 1101,1029[\mathrm{Cp} \quad \gamma \mathrm{C}-\mathrm{H}] ; 820[\mathrm{Cp} \delta \mathrm{C}-$ $\mathrm{H}] \mathrm{cm}^{-1} .{ }^{1} \mathrm{H}$ NMR $10.3(\mathrm{~m}, 1 \mathrm{H},-\mathrm{OH}) ; 6.9-7.8(\mathrm{~m}, 8 \mathrm{H}$, $\left.-\mathrm{C}_{6} \mathrm{H}_{4}-\mathrm{N}=\mathrm{N}-\mathrm{C}_{6} \mathrm{H}_{4}-\right)$; 4.0-4.5 (m, 9H, $\left.-\mathrm{Cp}\right) \cdot 1.5-1.6(\mathrm{~m}$, $\left.6 \mathrm{H},-\mathrm{C}\left(\mathrm{CH}_{3}\right)_{2}\right)$ ppm. 13C $\mathrm{NMR}\left(\mathrm{CDCl}_{3}, \delta\right): 161.2,150.9$, $145.3,132.0,124.9,122.5,116.0\left(-\mathrm{C}_{6} \mathrm{H}_{4}-\mathrm{N}=\mathrm{N}-\mathrm{C}_{6} \mathrm{H}_{4}-\right)$; 


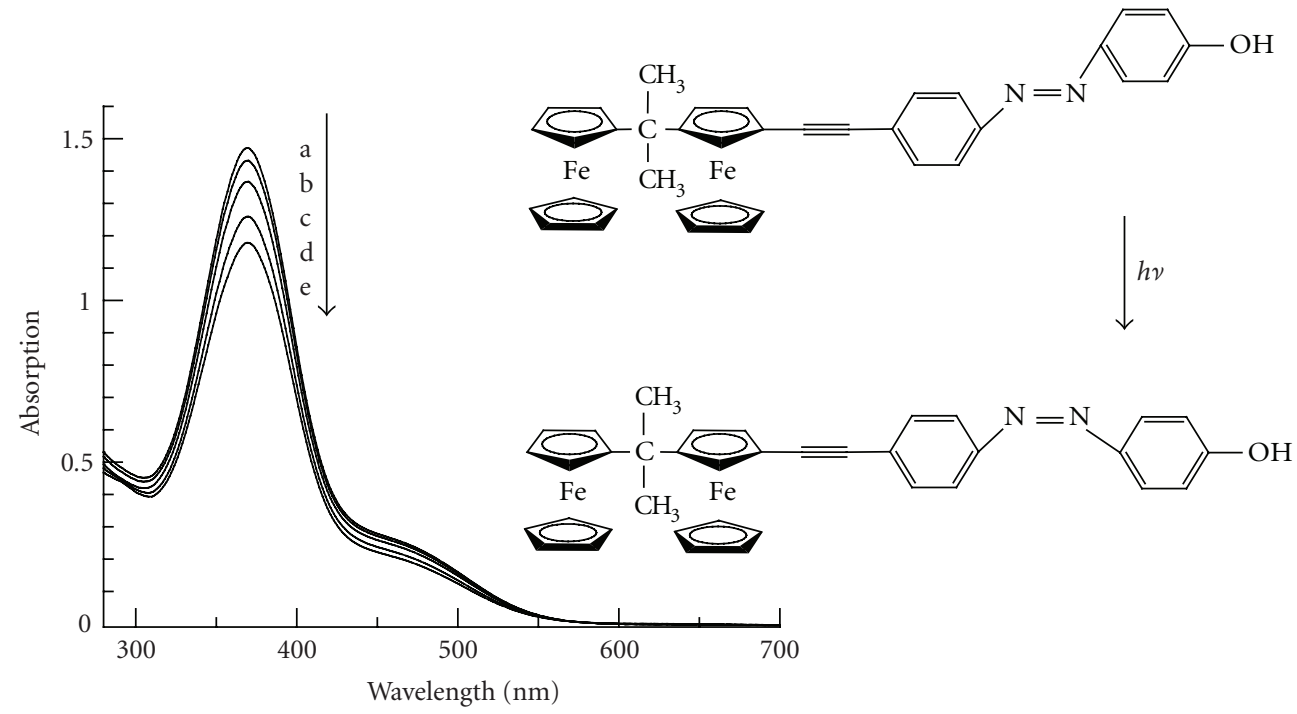

FIGURE 1: UV-vis absorption spectral change of DFAA (2 mM) in THF solution upon irradiation with UV light at $365 \mathrm{~nm}$ for (a) 30 minutes, (b) 50 minutes, (c) 70 minutes, (d) 90 minutes, (e) 100 minutes.

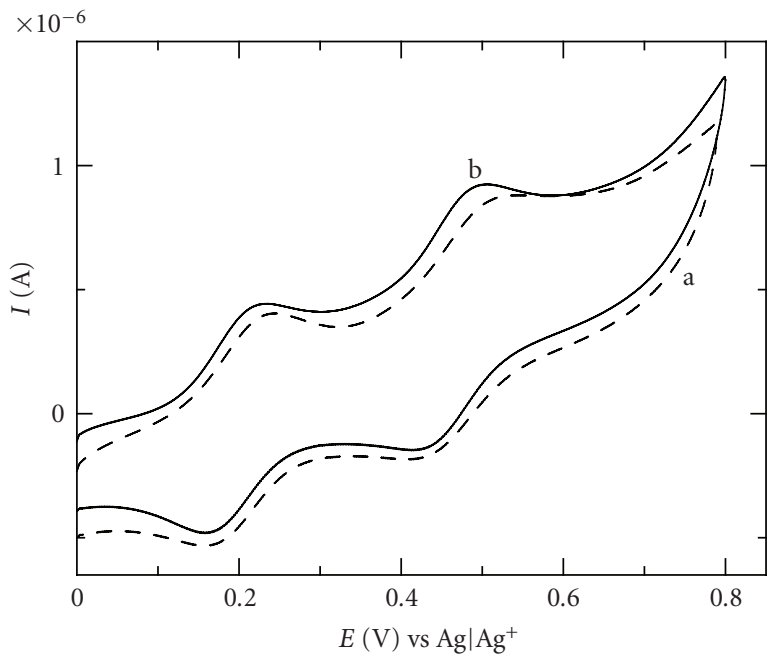

Figure 2: Cyclic voltammogram of DFAA in solution of $\mathrm{CH}_{2} \mathrm{Cl}_{2}-$ $\mathrm{Bu}_{4} \mathrm{NClO}_{4}(0.1 \mathrm{M})(\mathrm{a})$ before irradiation and (b) after irradiation.

91.4, 85.3(C $\equiv \mathrm{C}) ; 71.2,69.8,69.2,63.9$ (Cp) ppm. MS(EI) $632(\mathrm{M}+)$.

2.2. Characterization. IR spectra were recorded on a Nicolet FTIR spectrometer as $\mathrm{KBr}$ discs. Elemental analysis was carried out on an Elementar var III-type analyzer. ${ }^{1} \mathrm{H}$ and ${ }^{13} \mathrm{C}$ NMR spectra in $\mathrm{CDCl}_{3}$ were recorded on an Inova $500 \mathrm{FT}-$ $\mathrm{MHz}$ spectrometer. The mass spectra were determined using a Polaris QMS and a Micromass Autospec Ultima-TOF instrument. The electrochemical properties were determined with a CHI760C type analyzer. UV spectra were recorded on a Shimadzu UV-3150 spectrometer.

The quantum calculations were performed using Gaussian03 program [12]. The geometries of DFAA and the frequencies were evaluated using the DFT level of the three- parameter compound functional of Becke (B3LYP) [13]. The $6-31 G(d)$ basis set was used for all atoms. The geometry structures of neutral molecules were optimized under no constraint.

\section{Results and Discussions}

The synthesized DFAA was characterized using FT-IR, NMR, MS, and elemental analysis data. However, because there was an azo group in the molecule, the product may be a mixture of trans and cis configuration, it was very difficult to obtain a single crystal of DFAA.

3.1. UV Absorption Change. The UV-vis spectra of DFAA in tetrahydrofuran (THF) showed an intense azo $\pi-\pi^{*}$ band at $\lambda_{\max }=364 \mathrm{~nm}$ and a weak visible band at $450 \mathrm{~nm}$, the latter was primarily ascribable to a transition from the $e_{1 g}$ of ferrocene to the $\pi^{*}$ of azo group [14]. The irradiation of DFAA solution with $365 \mathrm{~nm}$ UV light led to a decrease in the absorbance of azo $\pi-\pi^{*}$ band, which indicated the trans-to-cis isomerization of DFAA (Figure 1), and the photostationary state (PSS) of DFAA at a nonradiation condition should be transconfiguration, or transform was a main configuration in mixture of trans and cis product.

3.2. Redox Potential Shift. The cyclic voltammogram of DFAA in THF solution containing a supporting electrolyte of $\mathrm{Bu}_{4} \mathrm{NClO}_{4}$ in a sealed thin quartz cell shows that there are two reversible $1 \mathrm{e}^{-}$oxidation waves at $\mathrm{E}=0.24$ and $0.51 \mathrm{~V}$ versus $\mathrm{Ag} / \mathrm{Ag}^{+}$reference electrode (Figure 2(a)). $\mathrm{E}=0.24 \mathrm{~V}$ was ascribed to the oxidation of ferrocene unit at position $\mathrm{B}$, and $0.51 \mathrm{~V}$ was the oxidation of ferrocene unit at position $\mathrm{A}$ because the withdrawing electron azo group and alkynyl were connected to it [15] (see Scheme 1). The potential difference between ferrocene unit $\mathrm{A}$ and $\mathrm{B}$ is $270 \mathrm{mV}$, which is similar to that of diferrocenyl propane derivatives [16]. After the 


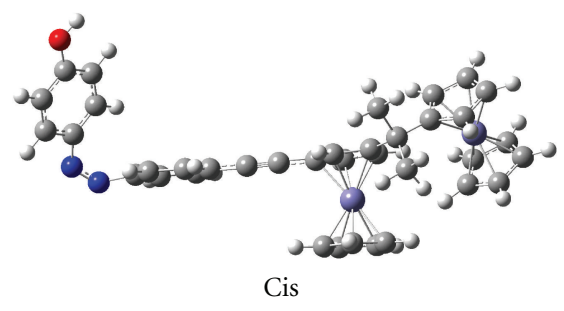

(a)

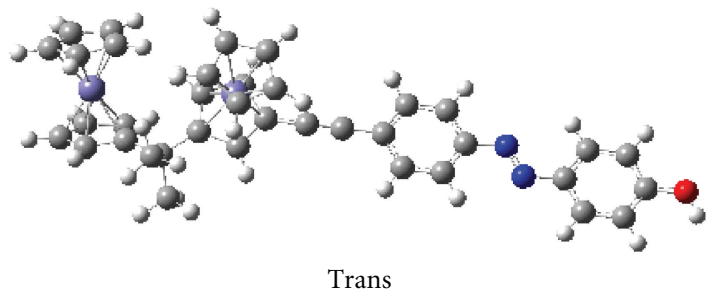

(b)

FIgUre 3: Optimized molecular structure of cis and trans DFAA.

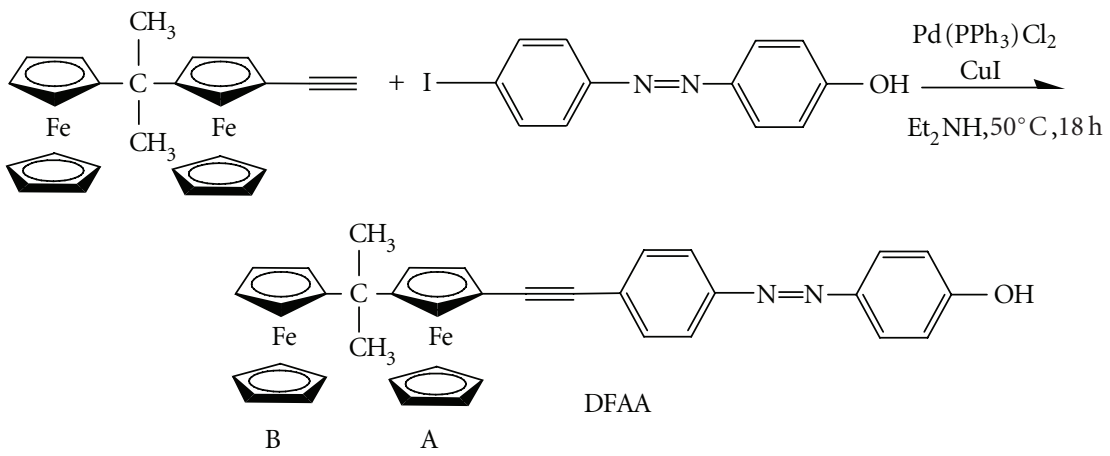

Scheme 1: Synthesis procedure of DFAA.

cell was irradiated with UV at $365 \mathrm{~nm}$ for 1.5 hours, we repeated the cyclic voltammetric measurement, oxidation potential at $0.51 \mathrm{~V}$ of ferrocene unit A negatively shifted to $0.48 \mathrm{~V}$ (Figure $2(\mathrm{~b})$ ), and there was no clear potential shift of ferrocenyl unit $\mathrm{B}$ in curve $\mathrm{a}$ and $\mathrm{b}$.

3.3. Calculations. In order to understand the change of absorbency and oxidation potential, the geometry of transDFAA was optimized by three parameterized Becke-LeeYang-Parr (B3LYP) hybrid exchange-correlation function [17]. In transoptimized structure (see Figure 3(b)), the azo and phenyl groups are located nearly on a plane in optimized molecular structure, the dihedral angle of $\mathrm{Ph}-\mathrm{N}=\mathrm{N}-\mathrm{Ph}$ was near to $0^{\circ}$, the $\mathrm{N}=\mathrm{N}$ bond length was $1.282 \AA$, and others structural data were consistent with documented reported [18]. Comparing to trans structural datas, cis-DFAA was also optimized by B3LYP/DFT (see Figure 3(a)), the resulted $\mathrm{N}=\mathrm{N}$ bond length was $1.265 \AA$, shorter than that of trans, and $\mathrm{Ph}-\mathrm{N}=\mathrm{N}-\mathrm{Ph}$ dihedral angle of cis-DFAA was $12^{\circ}$, similar to other cis-azobenezene derivatives $[19,20]$. Because two phenyls lose their coplanarity in the cis configuration, the $\pi$ electrons prefer to localize in $\mathrm{N}=\mathrm{N}$ bond compared to the large conjugated system of trans configuration. The bond length was shortened and electron withdrawing function of $\mathrm{N}=\mathrm{N}$ was reduced. Therefore, in the optimized structure of trans DFAA, the Mulliken charge numbers of Fe(II) in ferrocene units A and B (see Scheme 1) were 0.6210 and 0.6005 , respectively, and those of cis were 0.6110 and 0.6003 . For the ferrocene unit in position A, charge difference was 0.0100 between trans and cis configuration, with no apparent difference exhibited between trans and cis configuration in position B. This phenomenon may give us a possible reason for the oxidation potential of ferrocene A being slightly shifted negatively after irradiated by $365 \mathrm{~nm}$ light.

Calculated excitation energies in the trans and cis forms were in reasonable agreement with the experimental values. For the trans DFAA, molecular orbitals contributing to the main UV absorption at $364 \mathrm{~nm}$ was the excitation of electron from orbital 160 to 165 , not the excitation from the HOMO (164) to LUMO (165), and the oscillator strengths ( $\left.f_{\text {trans }}\right)$ contributed to this excitation was 0.8396 . For the cis DFAA, molecular orbitals contributing to the main UV absorption at $364 \mathrm{~nm}$ was the excitation of electron from orbitals of $160,159,158$ to 165 , not from HOMO (164) to LUMO (165). The oscillator strengths $\left(f_{\text {cis }}\right)$ contributed to excitation was 0.4072 . Comparing the calculated results, the excitation energy of trans and cis form was 3.4193 and $3.4173 \mathrm{eV}$, no apparent difference existed. However, the difference of oscillator strengths $(f)$ was obvious, $\Delta f$ value between the trans and cis was 0.4324 , this helped us to understand why the absorbance of trans-DFAA decreased with the irradiation of UV light at $365 \mathrm{~nm}$ and to identify the isomerization of trans to cis DFAA. MLCT (from Fe d orbital to azo $\pi$ orbital) band of DFAA in experimental and calculated results was not very obvious in the calculations of trans configuration; excitation at $462 \mathrm{~nm}$ with oscillator strengths $(f) 0.2698$ can be attributed to MLCT, but we did obtained the similar data in the calculations of cis form. The reason might be derived from the optimized structure of cis form, in which the ferrocene unit lost the conjugated plane, and the avenue of electron transfer from Fe $\mathrm{d}$ orbital to azo $\pi$ orbital is interdicted partially. 


\section{Conclusions}

In summary, the DFAA was synthesized by Sonogashira coupling reaction, and the phemomena of absorbance change and redox potential shift of DFAA were interpreted in terms of the optimization of structures and the singlet excitation calculations of DFAA, which indicated that the synthsized DFAA was mainly in trans configuration, but it could isomerize to a cis form by the irradiation of UV light with wavelength of $365 \mathrm{~nm}$.

\section{Acknowledgments}

This work was supported by Specialized Research Fund for the Doctoral Program of Higher Education of China (20060128001), Specialized Natural Science Fund of Inner Mongolia (200711020201), and Specialized Research Fund of Inner Mongolia University of Technology (ZD200704).

\section{References}

[1] K. Ichimura, S.-K. Oh, and M. Nakagawa, "Light-driven motion of liquids on a photoresponsive surface," Science, vol. 288, no. 5471, pp. 1624-1626, 2000.

[2] M. Fujino, S. Hasegawa, H. Akutsu, J. Yamada, and S. Nakatsuji, "Radical compounds and metal complexes with azobenzene chromophore," Polyhedron, vol. 26, no. 9-11, pp. 1989-1992, 2007.

[3] F. O. Koller, C. Sobotta, T. E. Schrader, et al., "Slower processes of the ultrafast photo-isomerization of an azobenzene observed by IR spectroscopy," Chemical Physics, vol. 341, no. 1-3, pp. 258-266, 2007.

[4] L. Wang and X. Wang, "An ab initio study of stable conformation and thermal isomerization of $p$-aminoazobenzene," Journal of Molecular Structure: THEOCHEM, vol. 806, no. 1-3, pp. 179-186, 2007.

[5] M. Kurihara, A. Hirooka, S. Kume, M. Sugimoto, and H. Nishihara, "Redox-conjugated reversible isomerization of ferrocenylazobenzene with a single green light," Journal of the American Chemical Society, vol. 124, no. 30, pp. 8800-8801, 2002.

[6] V. W.-W. Yam, V. C.-Y. Lau, and L.-X. Wu, "Synthesis, photophysical, photochemical and electrochemical properties of rhenium(I) diimine complexes with photoisomerizable pyridyl-azo, -ethenyl or -ethyl ligands," Journal of the Chemical Society, Dalton Transactions, no. 9, pp. 1461-1468, 1998.

[7] Q.-L. Suo, N. Zhu, L.-M. Han, Y.-B. Wang, Y.-G. Bai, and L.-H. Weng, "Studies on the synthesis of novel 2,2'bis(ferrocenyl)propane derivatives and their reactivity with metal carbonyl clusters," Polyhedron, vol. 25, no. 16, pp. 32093214, 2006.

[8] L.-M. Han, Q.-L. Suo, Y.-B. Wang, et al., "Ligand substitution reaction in the parent cluster $\left(\mu_{3} \mathrm{FcCHC}\right) \mathrm{FeCo}_{2}(\mathrm{CO})_{9}$ and structural characterization of its CO substituted derivatives," Polyhedron, vol. 24, no. 6, pp. 759-764, 2005.

[9] N. Zhu, Q.-L. Suo, Y.-B. Wang, L.-M. Han, Y.-G. Bai, and L.-H. Weng, "Synthesis, molecular structure and reactivity of new $\pi$-conjugated diyne with ferrocenyl and phenyl units," Polyhedron, vol. 26, no. 5, pp. 981-988, 2007.

[10] Q.-L. Suo, Y.-G. Bai, Y.-B. Wang, L.-M. Han, and L.-H. Weng, "Studies on the synthesis, characterization and reactivity of new ferrocenylacetylenylbiphenyl derivatives," Polyhedron, vol. 26, no. 13, pp. 3153-3160, 2007.

[11] Q.-L. Suo, L.-M. Han, Y.-B. Wang, et al., "Syntheses and molecular structures of new ferrocenylacetylide-bridged binuclear cobalt carbonyl cluster compounds," Journal of Coordination Chemistry, vol. 57, no. 17-18, pp. 1591-1601, 2004.

[12] M. J. Frisch, G. W. Trucks, H. B. Schlegel, et al., "Gaussian 03, Revision C.01,” Gaussian, Wallingford, Conn, USA, 2004.

[13] Y. Shimodaira, T. Miura, A. Kudo, and H. Kobayashi, "DFT method estimation of standard redox potential of metal ions and metal complexes," Journal of Chemical Theory and Computation, vol. 3, no. 3, pp. 789-795, 2007.

[14] N. Tamai and H. Miyasaka, "Ultrafast dynamics of photochromic systems," Chemical Reviews, vol. 100, no. 5, pp. 1875-1890, 2000.

[15] S. Xun, G. LeClair, J. Zhang, X. Chen, J. P. Gao, and Z. Y. Wang, "Tuning the electrical and optical properties of dinuclear ruthenium complexes for near infrared optical sensing," Organic Letters, vol. 8, no. 8, pp. 1697-1700, 2006.

[16] Y. Yuan, L. Zhang, A. Hu, J. Wang, W. Liu, and T. Ding, "Synthesis, characterization and electrochemical behaviour of 1 '-formyl [(2,2-diferrocenyl)propane]isonicotinoyl hydrazone and its lanthanide complexes," Polyhedron, vol. 18, no. 8-9, pp. 1247-1251, 1999.

[17] N. Kurita, S. Tanaka, and S. Itoh, "Ab initio molecular orbital and density functional studies on the stable structures and vibrational properties of trans- and cis-azobenzenes," The Journal of Physical Chemistry A, vol. 104, no. 34, pp. 81148120, 2000.

[18] M. Cossi, G. Scalmani, N. Rega, and V. Barone, "New developments in the polarizable continuum model for quantum mechanical and classical calculations on molecules in solution," The Journal of Chemical Physics, vol. 117, no. 1, pp. 43-54, 2002.

[19] A. Sakamoto, A. Hirooka, K. Namiki, et al., "Photon, electron-, and proton-induced isomerization behavior of ferrocenylazobenzenes," Inorganic Chemistry, vol. 44, no. 21, pp. 7547-7558, 2005.

[20] A. Mostad and C. Rømming, "A refinement of the crystal structure of cis-azobenzene," Acta Chemica Scandinavica, vol. 25, pp. 3561-3568, 1971. 


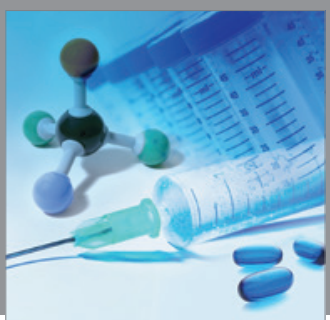

International Journal of

Medicinal Chemistry

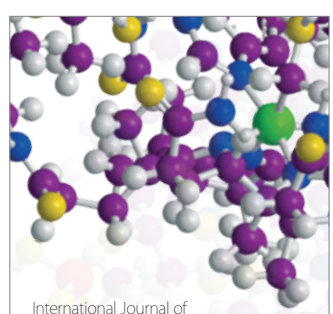

Carbohydrate Chemistry

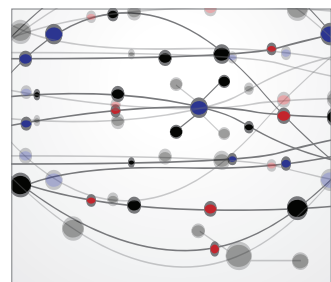

The Scientific World Journal
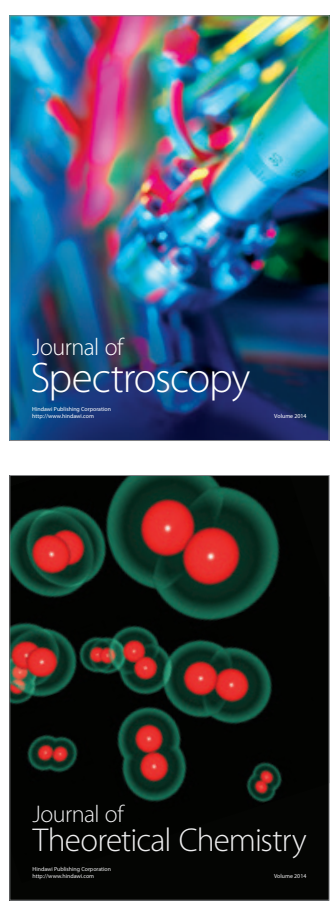
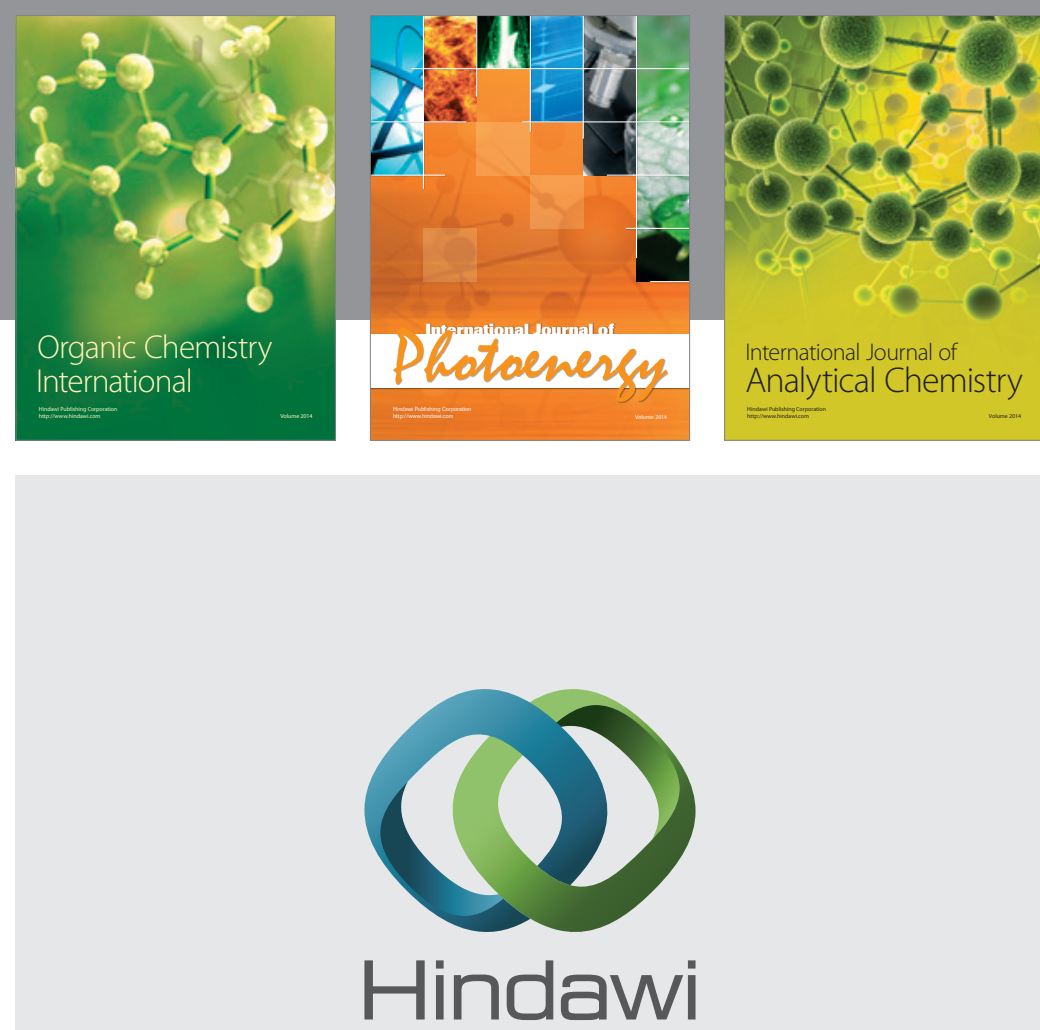

Submit your manuscripts at

http://www.hindawi.com
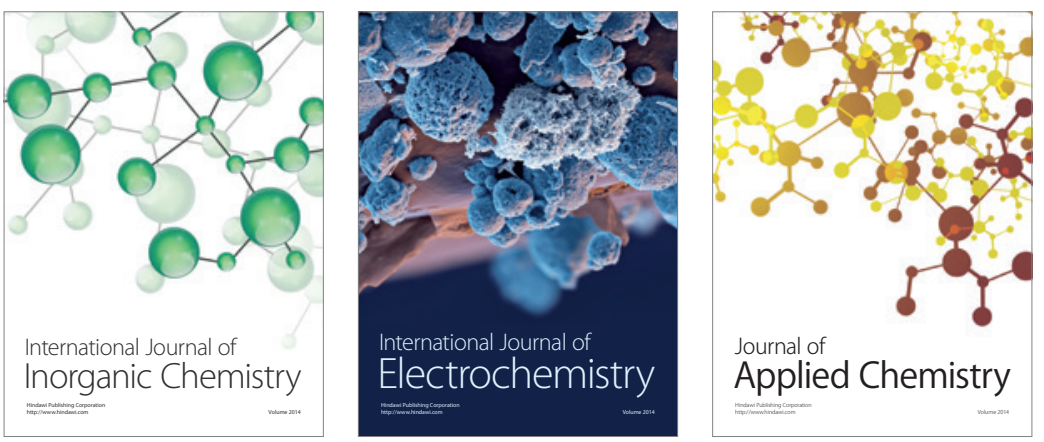

Journal of

Applied Chemistry
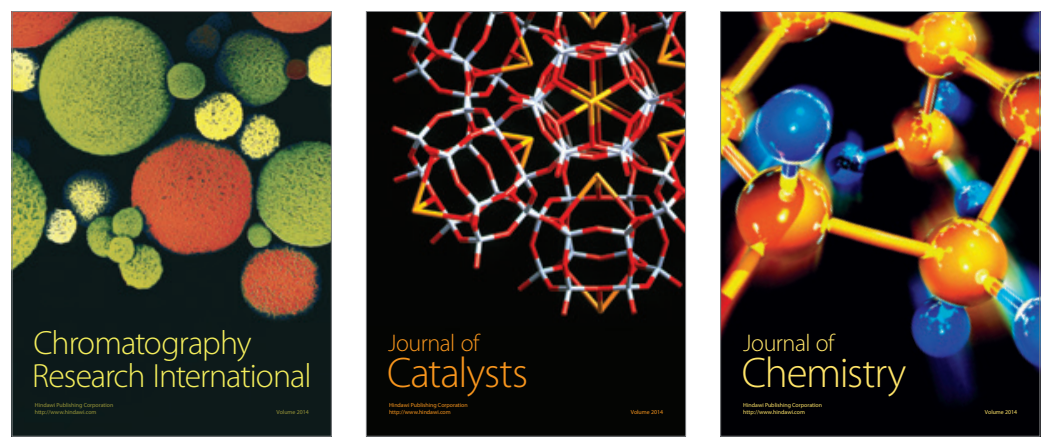
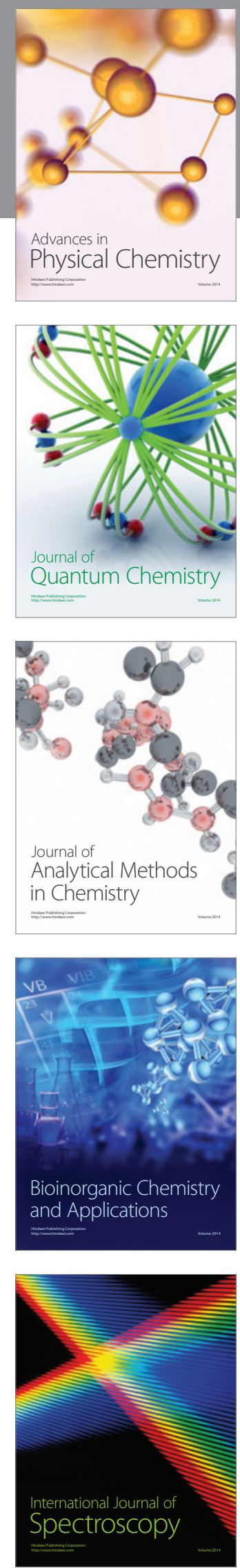